\title{
A Novel Acetyl-CoA Carboxylase 2 Selective Inhibitor Improves Whole-Body Insulin Resistance and Hyperglycemia in Diabetic Mice through Target-Dependent Pathways
}

\author{
Hiroyuki Takagi, Keiichi Tanimoto, Atsuyuki Shimazaki, Yutaka Tonomura, Sotaro Momosaki, \\ Shingo Sakamoto, Kohji Abe, Mitsuru Notoya, and Hideo Yukioka
}

Shionogi \& Co., Ltd., Osaka, Japan (H.T., K.T., A.S., Y.T., S.M., K.A., M.N., H.Y.) and Shionogi Techno Advance Research Co., Ltd., Osaka, Japan (S.S.)

Received November 11, 2019; accepted December 31, 2019

\begin{abstract}
Excess intramyocellular lipid (IMCL) deposition in skeletal muscle is closely associated with insulin resistance. Pharmacological inhibition of acetyl-CoA carboxylase (ACC) 2 offers a promising approach to treat insulin resistance through stimulation of mitochondrial fatty acid oxidation (FAO) and reduction of IMCL deposition. Previously reported experimental ACC2 inhibitors exhibited plasma glucose-lowering effects in diabetic rodents. However, their antidiabetic action may be potentially biased by off-target effects on triglyceride metabolism or by neurologic side effects. In this study, we investigated a safety profile, target dependency of its action, and antidiabetic efficacy of compound 2e, a novel olefin derivative potent ACC2 selective inhibitor. Four-day administration of suprapharmacological dose of compound $2 \mathrm{e}$ did not exhibit any obvious side effects in Sprague-Dawley rats. In $\mathrm{db} / \mathrm{db}$ mice, single administration of compound $2 \mathrm{e}$ led to significantly elevated $\mathrm{FAO}$ and reduced IMCL deposition in skeletal muscle. In ACC2 knockout mice, treatment with pharmacological doses of compound $2 e$ did not reduce plasma triglyceride levels, whereas A-908292, a previously reported ACC2 inhibitor, caused a significant triglyceride
\end{abstract}

reduction, showing that compound $2 \mathrm{e}$ was devoid of off-target triglyceride-lowering activity. Chronic treatment of $\mathrm{db} / \mathrm{db}$ mice with compound $2 \mathrm{e}$ improved hyperglycemia but did not decrease plasma triglyceride levels. Additionally, compound $2 \mathrm{e}$ showed significant improvements of whole-body insulin resistance in the clamp study and insulin tolerance test. Collectively, compound 2e demonstrated a good safety profile and significant antidiabetic effects through inhibition of ACC2-dependent pathways. These findings provide further evidence that selective inhibition of ACC2 is an attractive strategy against insulin resistance and type 2 diabetes.

\section{SIGNIFICANCE STATEMENT}

This study shows that pharmacological inhibition of acetyl-CoA carboxylase (ACC) 2 leads to significant improvements in wholebody glucose homeostasis, independently of off-target metabolic pathways and toxicity, which were observed in previously reported ACC2 inhibitors. These findings support the concept that ACC2-selective inhibitors will be a novel remedy for treatment of type 2 diabetes.

\section{Introduction}

Insulin resistance, a major contributing factor to type 2 diabetes, is closely associated with dysregulation of lipid metabolism in skeletal muscle. Except for endurance-trained athletes (Goodpaster et al., 2001), it has been generally accepted that intramyocellular lipid (IMCL) accumulation in skeletal muscle has a causal relationship with whole-body insulin resistance (Krssak et al., 1999; Virkamäki et al., 2001). Considerable evidence suggests that chronic overnutrition causes reduced fatty acid oxidation (FAO) and increased IMCL deposition in skeletal muscle, driving the development of insulin resistance (Kelley et al., 1999; Kim et al., 2000;

https://doi.org/10.1124/jpet.119.263590.
Morino et al., 2006). Therefore, the strategy designed to accelerate FAO and diminish IMCL deposition is considered as an attractive approach for treating type 2 diabetes.

Acetyl-CoA carboxylase (ACC), the enzyme that catalyzes production of malonyl-CoA from acetyl-CoA, has a great impact on lipid storage by regulating both synthesis and oxidation of fatty acids. ACC has two distinct isoforms, ACC1 and ACC2. ACC1 produces malonyl-CoA in cytosol and promotes de novo fatty acid synthesis in lipogenic tissues, such as liver and adipose tissues (Brownsey et al., 2006; Wakil and Abu-Elheiga, 2009). On the other hand, ACC2 suppresses FAO in oxidative tissues, such as skeletal muscle, through malonylCoA-regulated inhibition of carnitine palmitoyltransferase 1 , a key enzyme for long-chain acyl-CoA entry into mitochondrial FAO pathway (McGarry and Brown, 1997; Abu-Elheiga et al.,

ABBREVIATIONS: (S)-9c, (S)-N-(4-(2-(4-isopropoxyphenoxy)thiazol-5-yl)but-3-yn-2-yl)acetamide; A-908292, (S)-methyl(4-(2-(4-isopropoxyphenoxy)thiazol-5-yl)but-3-yn-2-yl)carbamate; $\mathrm{ACC}$, acetyl-CoA carboxylase; $\mathrm{AUC}_{0-24}$ hour, area under plasma concentration-time curve from 0 to 24 hours; BMIPP, $\beta$-methyl-p-iodophenyl-pentadecanoic acid; $\mathrm{C}_{\max }$, maximum plasma concentration; compound 2e, (S, E)-N-(4-(6-((7-chloro-2ethoxybenzo[d]thiazol-6-yl)oxy)pyridin-3-yl)but-3-en-2-yl)acetamide; EMCL, extramyocellular lipid; FAO, fatty acid oxidation; HbA1c, glycated hemoglobin; IMCL, intramyocellular lipid; LC-MS/MS, liquid chromatography-tandem mass spectrometry. 
2000; Brownsey et al., 2006; Wakil and Abu-Elheiga, 2009). Though whole-body deletion of ACC1 in mice is embryonic lethal (Abu-Elheiga et al., 2005), deletion of ACC2 in mice has been reported to decrease lipid accumulation by enhancing FAO in skeletal muscle and improve whole-body insulin resistance (Choi et al., 2007; Takagi et al., 2018). Pharmacological selective inhibition of ACC2 is thus currently regarded as a hopeful avenue for the therapy of insulin resistance.

To date, though many studies have reported the role of ACC2 in energy metabolism, only a few articles have described the antidiabetic effects of ACC2-selective inhibitors. A908292, the first published ACC2-selective inhibitor, showed significant reductions in plasma triglyceride and glucose levels inob/ob mice (Waring et al., 2008). However, its inactive enantiomer (R)-methyl(4-(2-(4-isopropoxyphenoxy)thiazol-5-yl)but-3-yn-2-yl)carbamate also showed similar effects (Waring et al., 2008). These results indicate that A-908292 could interfere with ACC2-independent metabolic pathways that have an impact on glucose homeostasis. In particular, its remarkable effect on triglyceride levels may be possibly attributed to the structure-based off-target action, considering the fact that genetic knockout of ACC2 did not show reduced triglyceride levels in high-fat diet-induced diabetic models (Choi et al., 2007; Takagi et al., 2018).

(S)-9c, another ACC2-selective inhibitor, was subsequently reported to show an acute reduction in skeletal muscle IMCL and then an improvement of hyperglycemia in $\mathrm{db} / \mathrm{db}$ mice (Glund et al., 2012), suggesting the possible links between ACC2-regulated IMCL breakdown and antidiabetic effects. However, (S)-9c has highly similar structure to A-908292 and showed a marked reduction in plasma triglyceride ( $\mathrm{Gu}$ et al., 2006; Glund et al., 2012), raising a considerable concern that (S)-9c may have the similar off-target metabolic effect to A-908292. Moreover, both A-908292 and (S)-9c have been reported to show structure-based neurologic toxicity (Gu et al., 2007), and there are not enough pharmacokinetic data to clarify relationships between their in vivo efficacy and toxicity. Therefore, despite much effort focusing on the therapeutic potential of ACC2 inhibition, it remains unclear whether pharmacological inhibition of ACC2 indeed has beneficial effects on glucose homeostasis, independently of off-target metabolic pathways and toxicity.

We have recently discovered compound 2e (Fig. 1), a novel olefin derivative, as a potent ACC2-selective inhibitor, with $\mathrm{IC}_{50}$ values of 1.9 and $1950 \mathrm{nM}$ for ACC2 and ACC1, respectively (Nishiura et al., 2018). In the present study, we evaluated a safety profile of compound $2 \mathrm{e}$ in healthy rats and examined its ACC2-dependent or -independent metabolic effects with db/db mice and ACC2 knockout mice. Furthermore, we investigated the therapeutic impact of chronic treatment with compound $2 \mathrm{e}$ on whole-body insulin sensitivity and hyperglycemia in $\mathrm{db} / \mathrm{db}$ mice under experimental conditions unaffected by off-target actions.

\section{Materials and Methods}

\section{Test Compounds}

Compound 2e and A-908292 were synthesized at the Shionogi Pharmaceutical Research Center (Osaka, Japan) according to the procedures described in previous reports (Gu et al., 2006; Nishiura et al., 2018). For toxicological study, compound 2e was dissolved in vehicle consisting of polyethylene glycol 400/Tween 80 (95:5 by

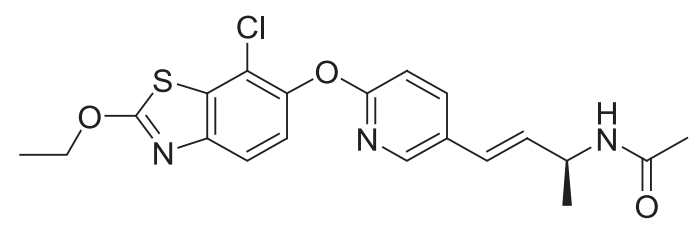

Fig. 1. Structure of compound 2e.

volume). For other experiments, compounds were suspended in $0.5 \%$ hydroxypropyl methylcellulose as vehicle. Compounds were administered to animals via the oral route.

\section{Animal Studies}

The study of fatty acid uptake was conducted at Osaka University Graduate School of Medicine (Osaka, Japan), and all the other studies were conducted at Shionogi Pharmaceutical Research Center. All procedures for animal studies were approved by the Institutional Animal Care and Use Committee of Shionogi \& Co., Ltd. (Osaka, Japan) or Osaka University Graduate School of Medicine. SpragueDawley rats were obtained from Charles River Japan (Kanagawa, Japan). BKS.Cg-+Lepr ${ }^{\mathrm{db}} /+\operatorname{Lepr}^{\mathrm{db}} / \mathrm{Jcl}(\mathrm{db} / \mathrm{db})$ mice and their nondiabetic controls $(\mathrm{db} / \mathrm{m})$ were obtained from CLEA Japan (Tokyo, Japan). ACC2 knockout mice and wild-type mice were generated as previously described (Takagi et al., 2018). All studies were performed using male animals. All experimental animals were single-housed in cages at a temperature-controlled $\left(20-23^{\circ} \mathrm{C}\right)$ environment under a 12-hour light/dark cycle and given access to a normal chow diet and water ad libitum. Rats and mice were fed CRF-1 (Charles River Japan) and CE-2 (CLEA Japan), respectively.

\section{Toxicological Study of Compound $2 e$ in Rats}

Six-week-old Sprague-Dawley rats were randomized into two groups based on body weight and then orally given compound $2 \mathrm{e}$ (50 mg/kg per day) or vehicle once a day for 4 consecutive days. Clinical signs were observed three times a day (before dosing, after dosing, and afternoon). Body weight and food intake were measured daily. After 4 days administration of compound $2 \mathrm{e}$, blood and tissue samples were collected from all rats. These collected samples were applied to hematology (complete blood count, differential white blood count, reticulocyte count, prothrombin time, and activated partial thromboplastin time), blood biochemistry (total protein, albumin, bilirubin, aspartate transaminase, alanine transaminase, alkaline phosphatase, lactate dehydrogenase, creatine kinase, amylase, urea nitrogen, creatinine, glucose, cholesterol, triglyceride, and electrolytes), and histopathology. For histopathological evaluation, H\&E-stained sections of major organs (brain, heart, liver, spleen, lung, kidney, thigh muscle, adrenal gland, duodenum, ileum, jejunum, pancreas, pituitary gland, stomach, testis, thymus, and thyroid gland) were assessed. In a separate study, 6 -week-old rats were orally given compound $2 \mathrm{e}$ $(50 \mathrm{mg} / \mathrm{kg})$, and blood samples were collected from the tail vein at 1,3 , 6,8 , and 24 hours after dosing for measurement of compound $2 \mathrm{e}$ concentrations.

\section{Single Dosing Studies of Compound $2 e$ in Mice}

Pharmacokinetic Profile. The pharmacokinetic profile of compound $2 \mathrm{e}$ was evaluated in 7 -week-old $\mathrm{db} / \mathrm{db}$ mice in the nonfasted state, following a single oral administration $(0.6$ or $5 \mathrm{mg} / \mathrm{kg})$. Blood samples were collected from the tail vein at 1, 3, 6, 8, 24, and 48 hours after dosing for measurement of compound 2e concentrations.

Evaluation of Malonyl-CoA Content in Skeletal Muscle. Tenweek-old db/db mice or 23-week-old ACC2 knockout mice were orally administered vehicle or compound $2 \mathrm{e}$ at the indicated doses in parallel with food removal. Mice were euthanized 6 hours after the administration, 
and the quadriceps muscle was rapidly dissected. The muscle samples were stored at $-80^{\circ} \mathrm{C}$ before analysis.

FAO. Indicators of FAO were examined in 8-12-week-old $\mathrm{db} / \mathrm{db}$ mice following a single oral administration of compound $2 \mathrm{e}$ at a dose of $2.5 \mathrm{mg} / \mathrm{kg}$. Fatty acid uptake in skeletal muscle was assessed using ${ }^{123} \mathrm{I}-\beta$-methyl-p-iodophenyl-pentadecanoic acid (BMIPP; Nihon Mediphysics Co. Ltd., Tokyo, Japan). Mice were intravenously injected with approximately $100 \mathrm{kBq}$ of ${ }^{123} \mathrm{I}$-BMIPP 4 hours after the single dosing of compound 2e. Blood and quadriceps muscle samples were collected 2 hours after the ${ }^{123}$ I-BMIPP injection, and radioactivity in the samples was measured with an automatic gamma-counter (Wizard 2480; PerkinElmer, Waltham, MA). The individual BMIPP uptake value was calculated as the ratio of quadriceps muscle to blood radioactivity. Acylcarnitine levels in quadriceps muscle (3 hours after dosing) as well as IMCL and extramyocellular lipid (EMCL) levels in tibialis anterior muscle (24 hours after dosing) were evaluated as previously described (Takagi et al., 2018).

\section{Evaluation of Triglyceride-Lowering Effects in ACC2 Knockout Mice}

ACC2 knockout mice at 21 weeks of age were randomized into three groups based on plasma triglyceride and glucose levels as well as body weight. Mice were orally given compound $2 \mathrm{e}(2.5 \mathrm{mg} / \mathrm{kg})$, A-908292 $(15 \mathrm{mg} / \mathrm{kg})$, or vehicle twice a day for 4 consecutive days. After 4 days administration, blood samples were collected from the tail vein in the nonfasted state and plasma triglyceride levels were measured.

\section{Long-Term Efficacy Studies of Compound $2 \mathrm{e}$ in $\mathrm{db} / \mathrm{db}$ Mice}

Evaluation of Antidiabetic Effect. Six-week-old $\mathrm{db} / \mathrm{db}$ mice were subjected to a habituation to oral administration for 1 week using $0.5 \%$ hydroxypropyl methylcellulose. At 7 weeks of age, mice were allocated to either the compound 2e- or vehicle-treated group based on body weight, food intake, plasma glucose levels, and glycated hemoglobin $(\mathrm{HbA1c})$ values. Mice were orally given compound $2 \mathrm{e}(1.7 \mathrm{mg} / \mathrm{kg})$ or vehicle twice a day for 8 weeks. Body weight and food intake were assessed daily. Blood metabolic parameters were measured between 5 and 7 weeks after the start of the treatment. Blood samples were collected from the tail vein under 5 -hour fasted (at 5 weeks), ad libitum-fed (at 6 weeks), or overnight fasted (at 7 weeks) conditions. At the end of study, blood samples were collected from inferior vena cava under isoflurane anesthesia in the nonfasted state at 18 hours after the final administration, and tissue samples (quadriceps muscle and pancreas) were immediately dissected for measurement of malonyl-CoA and insulin content. The samples were stored at $-80^{\circ} \mathrm{C}$ before analysis.

Evaluation of Whole-Body Insulin Sensitivity. db/db mice at 6 weeks of age (for hyperinsulinemic-euglycemic clamp study) or at 9 weeks of age (for insulin tolerance test) were subjected to the habituation and then to group allocation and treatment as described above. The clamp study was performed in mice treated with compound $2 \mathrm{e}$ or vehicle for 6 weeks as previously described (Takagi et al., 2018). Twenty percent glucose solution was used to maintain blood glucose levels in this study. Glucose infusion rate at the steady state was calculated from the average rate of 40 minutes of euglycemic conditions (approximately $90-130 \mathrm{mg} / \mathrm{dl}$ ). For the insulin tolerance test, mice treated with compound $2 \mathrm{e}$ or vehicle for 7 weeks were fasted for 5 hours and injected intraperitoneally with Humulin R $(0.8 \mathrm{U} / \mathrm{kg}$; Eli Lilly, Kobe, Japan). Blood samples were collected from the tail vein at $0,30,60,90$, and 120 minutes after injection. A glucometer (Arkray, Tokyo, Japan) was used to measure blood glucose concentrations in the samples.

\section{Measurements}

Determination of Toxicokinetic and Pharmacokinetic Parameters of Compound 2e. Plasma samples were prepared from blood samples by centrifugation. Plasma concentrations of compound $2 \mathrm{e}$ were determined by liquid chromatography-tandem
TABLE 1

Toxicological study of compound $2 \mathrm{e}$ in rats

Male Sprague-Dawley rats at the age of 6 wk were orally given compound $2 \mathrm{e}$ at $50 \mathrm{mg} / \mathrm{kg}$ per day for 4 days, and toxicological parameters were compared with vehicle-treated group ( $n=3$ /group). Toxicokinetic parameters were evaluated in 6 wk-old Sprague-Dawley rats after a single oral administration of compound $2 \mathrm{e}$ at $50 \mathrm{mg} / \mathrm{kg}(n=2)$. Values are presented as means \pm S.E.M.

\begin{tabular}{|c|c|}
\hline Parameter & Results \\
\hline Body weight & No significant difference from vehicle group \\
\hline Food intake & No significant difference from vehicle group \\
\hline Clinical signs & $\begin{array}{c}\text { No abnormalities in general appearance and } \\
\text { behavior. Loose stool was observed in both } \\
\text { groups (one-third rat) }\end{array}$ \\
\hline Histopathology & No histopathological abnormalities \\
\hline Hematology & No significant difference from vehicle group \\
\hline $\begin{array}{l}\text { Blood biochemical } \\
\text { parameters }\end{array}$ & $\begin{array}{l}\text { Mild increase in plasma total cholesterol } \\
\text { (vehicle vs. compound } 2 \mathrm{e}: 76 \pm 7 \mathrm{mg} / \mathrm{dl} \text { vs. } \\
101 \pm 3 \mathrm{mg} / \mathrm{dl} ; P<0.05 \text { ) }\end{array}$ \\
\hline \multicolumn{2}{|l|}{$\begin{array}{l}\text { Toxicokinetic } \\
\text { parameters }\end{array}$} \\
\hline $\begin{array}{c}-\mathrm{AUC}_{0-24} \text { hour } \\
(\mu \mathrm{g} * \mathrm{~h} / \mathrm{ml})\end{array}$ & $620 \pm 105$ \\
\hline$-\mathrm{C}_{\max }(\mu \mathrm{g} / \mathrm{ml})$ & $34.6 \pm 5.0$ \\
\hline$-\mathrm{C}_{24 \text { hour }}(\mu \mathrm{g} / \mathrm{ml})$ & $17.5 \pm 4.4$ \\
\hline
\end{tabular}

mass spectrometry (LC-MS/MS) analyses using API5000 with Analyst (AB Sciex, Framingham, MA). The area under plasma concentration-time curve from 0 to 24 hours $\left(\mathrm{AUC}_{0-24}\right.$ hour $)$, maximum plasma concentration $\left(\mathrm{C}_{\max }\right)$, and trough plasma concentration were calculated from the observed plasma concentration data at the sampling time points.

Blood Metabolic Parameters. Plasma and blood cell layer were obtained from blood samples by centrifugation at $22,400 \mathrm{~g}$ for 5 minutes at $4^{\circ} \mathrm{C}$. Plasma glucose, plasma triglyceride, and $\mathrm{HbA} 1 \mathrm{c}$ levels were determined by enzymatic methods using a Hitachi 7180 automatic analyzer (Hitachi, Tokyo, Japan). Plasma insulin concentration was measured using a mouse insulin ELISA kit (Shionogi, Osaka, Japan) (Imai et al., 2015).

Determination of Malonyl-CoA Content. Frozen muscle samples were homogenized on ice using hand-held homogenizers in distilled water $/ 60 \%$ perchloric acid/85\% phosphoric acid (43:5:2 by volume) with the ratio of 1:10 (w/v). After centrifugation, the supernatant was transferred into LC-MS/MS system. LC-MS/MS system was performed on a Waters Micromass Quattro Ultima Pt (Micromass, Manchester, UK).

Measurement of Pancreatic Insulin Content. Frozen pancreas samples were homogenized on ice using hand-held homogenizers in $99.5 \%$ ethanol/distilled water/6 $\mathrm{N}$ hydrochloric acid (30:9:1 by volume) with the ratio of $1: 6(\mathrm{w} / \mathrm{v})$. After standing at $4^{\circ} \mathrm{C}$ overnight, samples were centrifugated, and insulin concentrations in the supernatant were determined using a mouse insulin ELISA kit (Shionogi) (Imai et al., 2015).

\section{Statistical Analysis}

For long-term efficacy studies, the uniformity of the parameters for group assignment was confirmed by one-way analysis of variance. All results are presented as means \pm S.E.M. Statistical comparisons between groups were analyzed by Student's $t$ test. Statistical significance was set at $P<0.05$.

\section{Results}

Toxicological Study of Compound $2 \mathrm{e}$ in Rats. Toxicological findings in the rats treated with compound $2 \mathrm{e}$ for 4 days at $50 \mathrm{mg} / \mathrm{kg}$ per day are shown in Table 1 . In the clinical signs, there were no findings except for loose stool, which was observed in both groups and therefore considered to be due to the vehicle administration. Body weight and food intake were not affected by the treatment, and no abnormalities were 

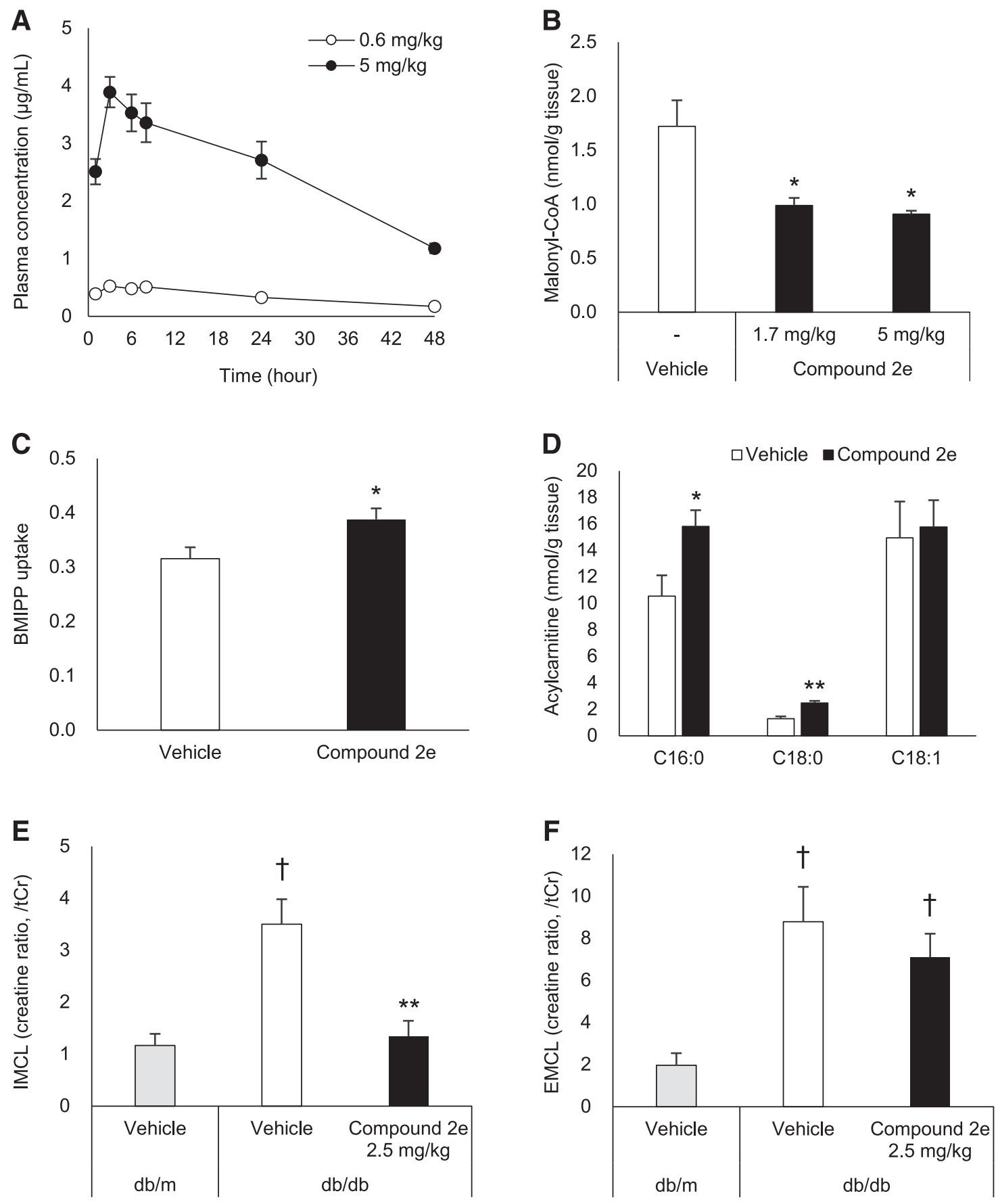

Fig. 2. Pharmacokinetic and pharmacological profiles of compound $2 \mathrm{e}$ in db/db mice. (A) Concentration-time profiles of compound $2 \mathrm{e}$ in plasma after oral administration of compound $2 \mathrm{e}$ at a dose of $0.6 \mathrm{or} 5 \mathrm{mg} / \mathrm{kg}$ in $\mathrm{db} / \mathrm{db}$ mice $(n=3)$. (B) Malonyl-CoA levels in skeletal muscle $6 \mathrm{hours}$ after oral administration of vehicle or compound $2 \mathrm{e}(1.7$ or $5 \mathrm{mg} / \mathrm{kg})$ in $\mathrm{db} / \mathrm{db}$ mice $(n=4)$. (C-F) The effects of compound 2e on skeletal muscle lipid metabolism were evaluated in $\mathrm{db} / \mathrm{db}$ mice following a single oral administration of compound $2 \mathrm{e}$ at a dose of $2.5 \mathrm{mg} / \mathrm{kg}(n=4-7)$. The uptake values of ${ }^{123} \mathrm{I}-\beta$-methylp-iodophenyl-pentadecanoic acid (BMIPP) in skeletal muscle were represented by the ratio of quadriceps muscle to blood radioactivity (C). Acylcarnitine levels in skeletal muscle of db/db mice (D). Intramyocellular lipid (IMCL) levels (E) and extramyocellular lipid (EMCL) levels (F) in skeletal muscle of db/ $\mathrm{db}$ or $\mathrm{db} / \mathrm{m}$ mice. IMCL and EMCL values were calculated as the ratio to total creatine (tCr). ${ }^{*} P<0.05 ; * * P<0.01$ vs. vehicle-treated mice; ${ }^{\dagger} P<0.01 \mathrm{vs}$. $\mathrm{db} / \mathrm{m}$ mice. All data are presented as means \pm S.E.M.

found in hematology and histopathology. Only total plasma cholesterol value was mildly elevated, but there were no related findings in histopathological findings, and all the other blood chemistry parameters were unaffected. In addition, the systemic exposure of compound $2 \mathrm{e}$ at $50 \mathrm{mg} / \mathrm{kg}$ was the $\mathrm{C}_{\max }$ value of $34.6 \mu \mathrm{g} / \mathrm{ml}$ and the $\mathrm{AUC}_{0-24}$ hour value of $620 \mu \mathrm{g} * \mathrm{~h} / \mathrm{ml}$, which were much higher than in pharmacology studies. Taken together, the rats given compound $2 \mathrm{e}$ at $50 \mathrm{mg} / \mathrm{kg}$ per day were well tolerated.

Pharmacokinetic Profiles and Acute Pharmacological Actions of Compound $2 \mathrm{e}$ in $\mathbf{~ d b / d b}$ Mice. We evaluated pharmacokinetic parameters and ACC2 inhibitory action of compound $2 \mathrm{e}$ in $\mathrm{db} / \mathrm{db}$ mice. Compound 2e showed good plasma exposure and dose-dependent pharmacokinetics at 

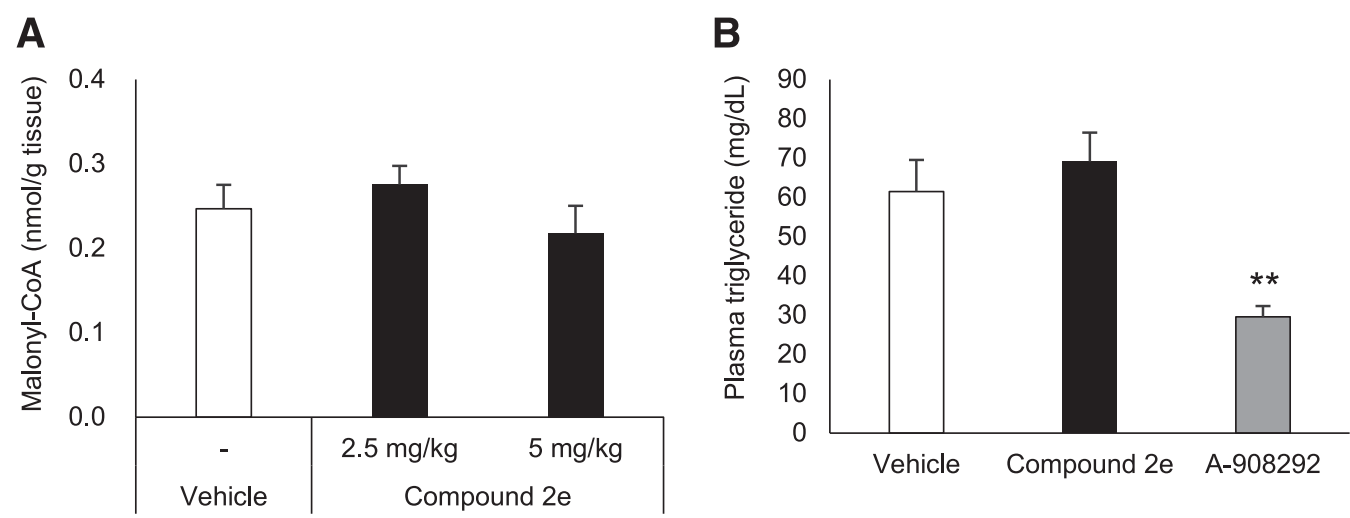

Fig. 3. Evaluation of target specificity using ACC2 knockout mice. (A) Malonyl-CoA levels in skeletal muscle 6 hours after oral administration of vehicle or compound $2 \mathrm{e}(2.5$ or $5 \mathrm{mg} / \mathrm{kg})$ in ACC2 knockout mice $(n=5)$. (B) Off-target effects of ACC2 inhibitors on plasma triglyceride levels were evaluated in ACC2 knockout mice. Mice were orally given compound $2 \mathrm{e}(2.5 \mathrm{mg} / \mathrm{kg}), \mathrm{A}-908292(15 \mathrm{mg} / \mathrm{kg})$, or vehicle twice a day for 4 consecutive days. After 4 days administration, plasma triglyceride levels were measured $(n=7)$. ** $P<0.01$ vs. vehicle-treated mice. All data are presented as means \pm S.E.M.

oral doses of 0.6 and $5 \mathrm{mg} / \mathrm{kg}$ (Fig. 2A). A dose of $5 \mathrm{mg} / \mathrm{kg}$ showed the $\mathrm{C}_{\max }$ value of $3.9 \mu \mathrm{g} / \mathrm{ml}$ and the $\mathrm{AUC}_{0-24}$ hour value of $74.2 \mu \mathrm{g} * \mathrm{~h} / \mathrm{ml}$, which were much (over eight times) lower than those in toxicological studies in rats. After single oral administration of compound $2 \mathrm{e}$ at doses of 1.7 and $5 \mathrm{mg} / \mathrm{kg}$, skeletal muscle malonyl-CoA levels were significantly decreased (Fig. 2B). Single-dose treatment of compound $2 \mathrm{e}$ at $2.5 \mathrm{mg} / \mathrm{kg}$ elevated uptake of BMIPP, a fatty acid analog, and increased long-chain acylcarnitine levels in skeletal muscle, both as indicators of FAO (Fig. 2, C and D). Furthermore, compound $2 \mathrm{e}$ treatment acutely reduced skeletal muscle IMCL levels in $\mathrm{db} / \mathrm{db}$ mice to the levels of nondiabetic control $\mathrm{db} / \mathrm{m}$ mice (Fig. 2E). Interestingly, despite these significant elevations in fatty acid metabolism, compound $2 \mathrm{e}$ treatment did not reduce skeletal muscle EMCL levels in $\mathrm{db} / \mathrm{db}$ mice (Fig. 2F), consistent with a previous observation in ACC2 knockout mice (Takagi et al., 2018). These results suggest that compound 2e enhanced FAO and lipid breakdown by ACC2 inhibitory action in skeletal muscle.

Evaluation of Target Specificity Using ACC2 Knockout Mice. We next assessed target specificity of compound $2 \mathrm{e}$ using ACC2 knockout mice. In contrast to the results in $\mathrm{db} / \mathrm{db}$ mice, no significant reductions in malonyl-CoA levels were observed in ACC2 knockout mice with compound 2e at doses of 2.5 and $5 \mathrm{mg} / \mathrm{kg}$ (Fig. 3A). To determine whether compound $2 \mathrm{e}$ has similar off-target activity to A-908292, we compared its triglyceride-lowering effect with that of A-908292 in the shorttreatment study. Four-day treatment with compound $2 \mathrm{e}$ $(2.5 \mathrm{mg} / \mathrm{kg}$ twice daily) did not affect plasma triglyceride levels in ACC2 knockout mice, whereas A-908292 $(15 \mathrm{mg} / \mathrm{kg}$ twice daily) markedly reduced plasma triglyceride levels (Fig. 3B), consistent with a previous report (Waring et al., 2008). These results indicate that compound 2e did not have such an off-target activity as to interfere with triglyceride metabolism independently of ACC2 inhibition, at least in pharmacological doses.

Antidiabetic Effect of Long-Term Treatment with Compound 2e in db/db Mice. The results of our short-term studies in mice indicate that a dose of $2.5 \mathrm{mg} / \mathrm{kg}$ compound $2 \mathrm{e}$ was adequate to induce ACC2 inhibitory action without the off-target metabolic effect. Based on the pharmacokinetic data of the relatively long half-life of compound $2 \mathrm{e}$ in mice (Fig. 2A), we adopted a dose of $1.7 \mathrm{mg} / \mathrm{kg}$ for the following long-term studies. To investigate antidiabetic effect, compound $2 \mathrm{e}$ was orally administrated to $\mathrm{db} / \mathrm{db}$ mice at a dose of $1.7 \mathrm{mg} / \mathrm{kg}$ twice daily ( $3.4 \mathrm{mg} / \mathrm{kg}$ per day) for 8 weeks. Body weight of mice treated with compound $2 \mathrm{e}$ was similar to that of vehicletreated mice until 6 weeks and was slightly but significantly higher at 7-8 weeks (Fig. 4A). No significant difference in food intake was observed between both groups of mice throughout the study (Fig. 4B). Compared with vehicle-treated mice, compound 2e-treated mice showed significant decreases in blood glucose levels at 5 weeks (Fig. 4C) and HbA1c values at 6-7 weeks $(0.64 \%$ points lower than vehicle-treated mice at 7 weeks; Fig. 4D). There were no reductions in plasma triglyceride levels of compound 2e-treated mice (Fig. 4E). Plasma insulin levels were slightly but not significantly higher in compound 2e-treated mice $(P=0.09$ at 7 weeks; Fig. $4 \mathrm{~F}$ ), and no significant change in pancreatic insulin content was detected after compound 2e treatment (Fig. 4G). At the end of the study, pharmacokinetics and pharmacodynamics were assessed. Plasma concentration of compound $2 \mathrm{e}$ at 6 and 18 hours after the final administration were 1.7 and $0.8 \mu \mathrm{g} / \mathrm{ml}$, respectively, which were more than 10-times lower than trough plasma concentration in the safety assessment study in rats (Table 1). Skeletal muscle malonyl-CoA levels were markedly reduced at 18 hours after the final administration compared with vehicle treatment (Fig. $4 \mathrm{H})$. This reduction suggests that ACC2 inhibitory action was maintained throughout the study.

Impact of Compound $2 e$ on Whole-Body Insulin Sensitivity in $\mathbf{d b} / \mathbf{d b}$ Mice. To further investigate the antidiabetic effect of compound $2 \mathrm{e}$, we evaluated whole-body insulin sensitivity in $\mathrm{db} / \mathrm{db}$ mice by hyperinsulinemiceuglycemic clamp and the insulin tolerance test. Steadystate glucose infusion rate in the clamp study was markedly increased in mice treated with compound $2 \mathrm{e}$ for 6 weeks compared with vehicle-treated mice (Fig. 5A). Likewise, insulin-stimulated glucose disposal in the insulin tolerance test was significantly improved in mice treated with compound $2 \mathrm{e}$ for 7 weeks (Fig. 5B). These results suggest that improved insulin sensitivity greatly contributed to glucoselowering effect of compound $2 \mathrm{e}$.

\section{Discussion}

Previous studies have revealed that ACC2 knockout mice showed favorable phenotype of improved glucose homeostasis, providing a notion of ACC2 as an antidiabetic target 

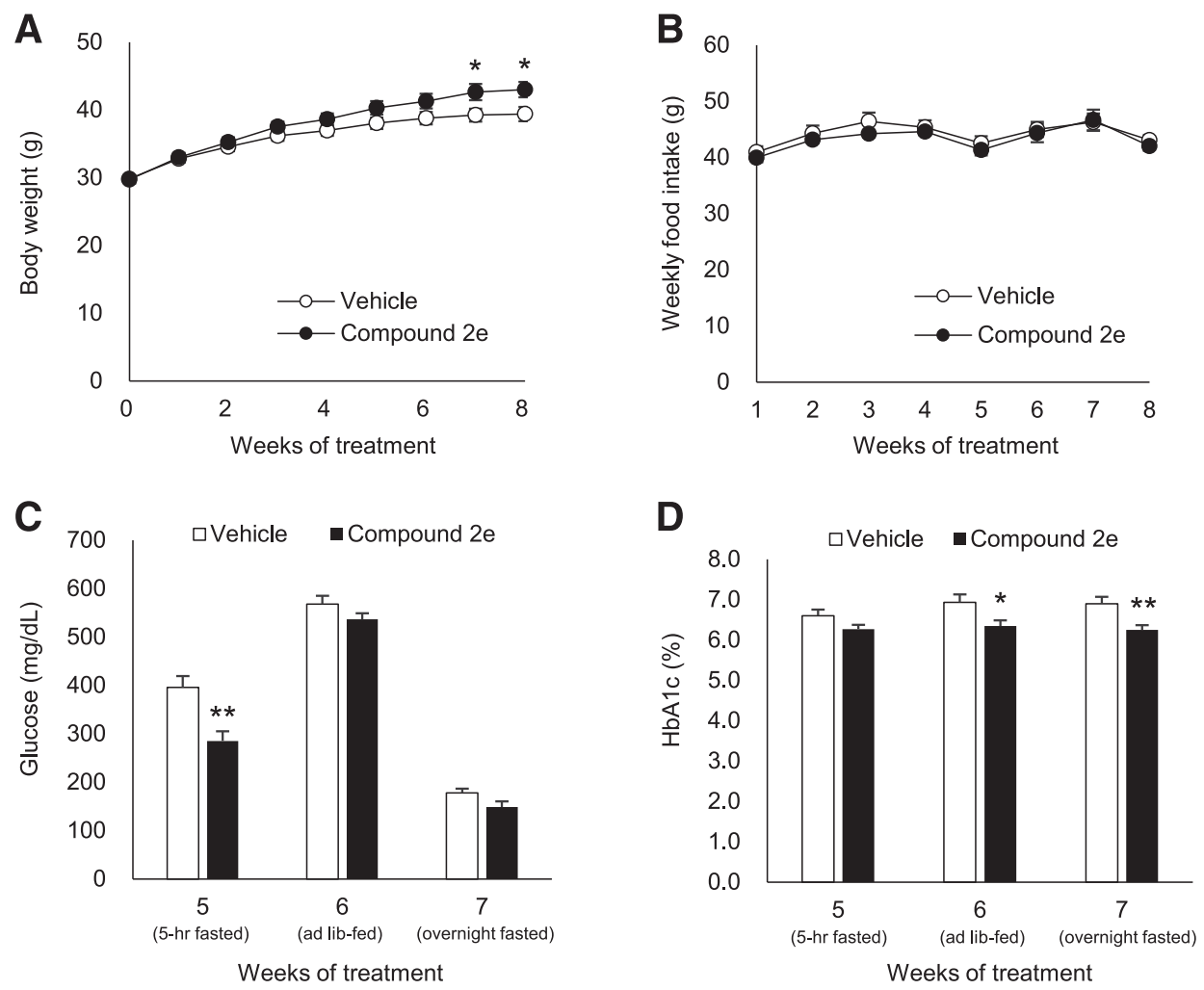

Fig. 4. Antidiabetic effect of long-term treatment with compound $2 \mathrm{e}$ in $\mathrm{db} / \mathrm{db}$ mice. Compound $2 \mathrm{e}$ was orally administered to $\mathrm{db} / \mathrm{db}$ mice at a dose of $1.7 \mathrm{mg} / \mathrm{kg}$ twice daily $(3.4 \mathrm{mg} / \mathrm{kg}$ per day) for 8 weeks. Body weight (A) and weekly food intake (B) in $\mathrm{db} / \mathrm{db}$ mice $(n=8$ to 9 ). (C-F) Blood metabolic parameters were evaluated under 5-hour fasted (at 5 weeks), ad libitum-fed (at 6 weeks), or overnight-fasted (at 7 weeks) conditions $(n=8-9)$. Plasma glucose (C), glycated hemoglobin (D),

$\mathbf{F}$
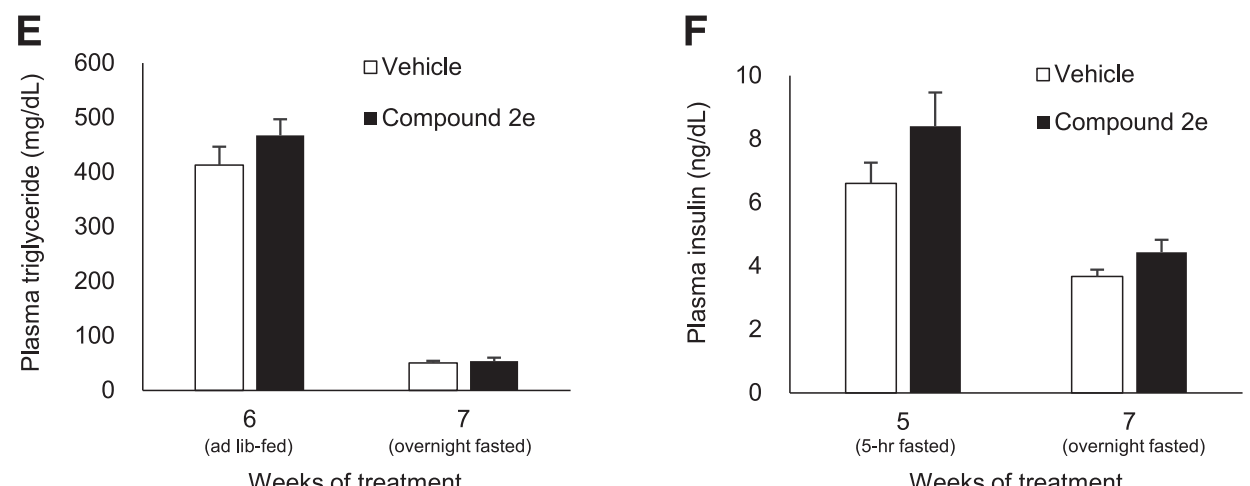
plasma triglyceride (E), and plasma insulin (F) levels. At the end of the study, pancreatic insulin levels $(G)$ and skeletal muscle malonyl-CoA content $(\mathrm{H})$ were evaluated in nonfasted mice at 18 hours after the final administration $(n=6) .{ }^{*} P<0.05$; ${ }^{*} * P<0.01$ vs. vehicle-treated mice. All data are presented as means \pm S.E.M.
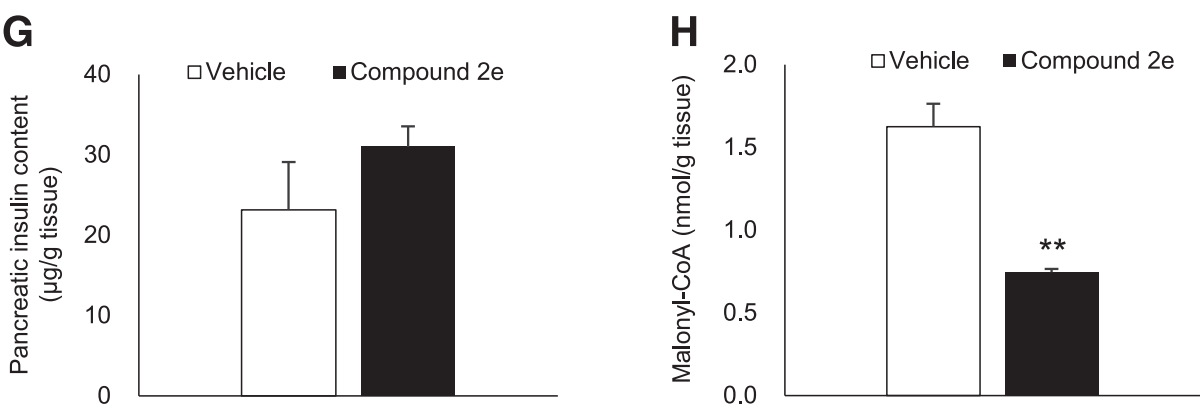

(Choi et al., 2007; Takagi et al., 2018). Genetic manipulations, however, have potential limitations, such as complete absence of target molecule and nonuniformity of gene knockout strategy, which may partially account for phenotypic discrepancies between several lines of ACC2 knockout mice (Hoehn et al., 2010, 2012; Olson et al., 2010). Therefore, pharmacological studies are required to validate the therapeutic potential of ACC2 inhibition. Unfortunately, previously reported ACC2 inhibitors were shown to potentially cause serious side effects or significantly affect cellular metabolic pathways, independently of ACC2 inhibition (Gu et al., 2007; Waring et al., 2008). The aim of this study was to determine the antidiabetic potential of ACC2 inhibition at pharmacological doses without obvious ACC2independent action and toxicity, using a novel smallmolecule ACC2 selective inhibitor, compound 2e. 
A

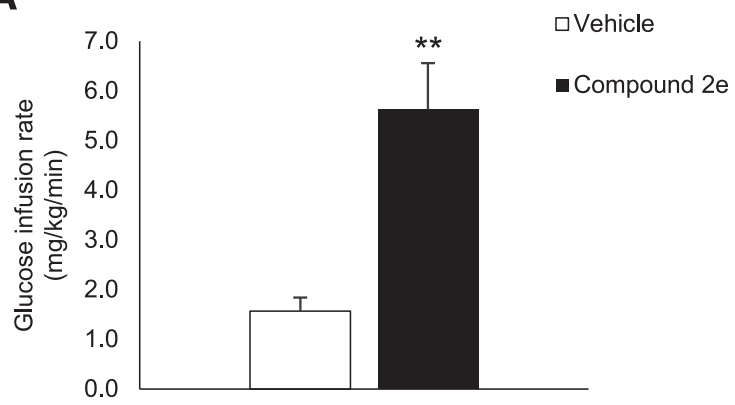

B
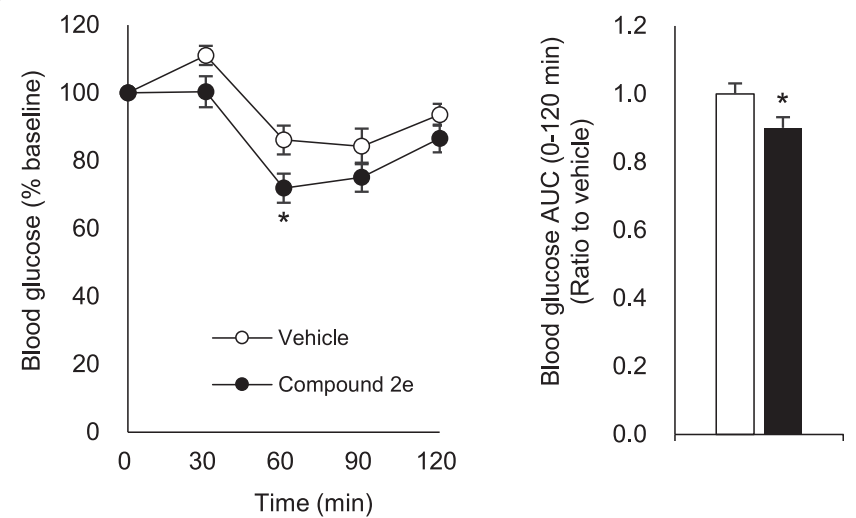

Fig. 5. Impact of compound $2 \mathrm{e}$ on whole-body insulin sensitivity in $\mathrm{db} / \mathrm{db}$ mice. Compound $2 \mathrm{e}$ was orally administrated to $\mathrm{db} / \mathrm{db}$ mice at a dose of $1.7 \mathrm{mg} / \mathrm{kg}$ twice daily ( $3.4 \mathrm{mg} / \mathrm{kg}$ per day) for 6 or 7 weeks. (A) After 6 weeks of treatment with compound 2e, the hyperinsulinemic-euglycemic clamp was conducted with continuous infusion of human insulin $(10.5 \mathrm{mU} / \mathrm{kg}$ per minute) in overnight-fasted mice. Glucose infusion rate at the steady state was obtained from the average rate of 40 minutes of euglycemic conditions (approximately $90-130 \mathrm{mg} / \mathrm{dl})(n=5-7)$. (B) After 7 weeks of treatment with compound $2 \mathrm{e}$, the insulin tolerance test was conducted with intraperitoneal injection of human insulin $(0.8 \mathrm{U} / \mathrm{kg})$ in 5 -hour fasted mice $(n=9-10)$. $* P<0.05 ; * * P<0.01$ vs. vehicle-treated mice. All data are presented as means \pm S.E.M.

One crucial issue related to ACC2 inhibitors is the structure-based off-target metabolic effect as exemplified in a study of short treatment with A-908292 (Waring et al., 2008). Based on the report by Abbott group, these off-target effects, characterized by a striking plasma triglyceride reduction, was probably through indirect activation of a peroxisome proliferator-activated receptor- $\alpha$ pathway. In addition, (S)-9c, another ACC2 inhibitor, also showed a marked reduction in plasma triglyceride (Glund et al., 2012). Notably, despite its great structural similarity with A-908292, no description and no data have been presented to identify the ACC2-dependent or -independent effects of (S)-9c. Because plasma triglyceride levels or peroxisome proliferator-activated receptor- $\alpha$ signaling pathways can greatly impact glucose homeostasis (Ye et al., 2001; Kim et al., 2003), previous studies using these inhibitors may not be sufficient to determine therapeutic efficacy of ACC2-specific inhibition. In the present study, administration of A-908292 caused acute reductions of plasma triglyceride levels in ACC2 knockout mice, further demonstrating its off-target effect observed in the previous study. Notably, in contrast to A-908292, short-term treatment with compound $2 \mathrm{e}$ did not evoke an ACC2-independent plasma triglyceride reduction, indicating that compound $2 \mathrm{e}$ was devoid of such off-target effects as to interfere with triglyceride metabolism and that ACC2 inhibition per se does not directly reduce plasma triglyceride levels, at least in the short period. In db/db mice, compound 2e treatment acutely decreased malonyl-CoA content, increased FAO, and diminished IMCL levels in skeletal muscle, as reasonably expected actions from ACC2 inhibition. Furthermore, the present observation that chronic treatment with compound 2e led to improved glucose homeostasis without affecting plasma triglyceride levels agreed well with the previous reports describing the phenotypes of ACC2 knockout mice (Choi et al., 2007; Takagi et al., 2018). Collectively, these results indicate that compound $2 \mathrm{e}$ treatment improves glucose homeostasis through the target-dependent pathway.

Neurologic toxicity is another concern about previously reported ACC2 inhibitors. Both A-908292 and (S)-9c were reported to show neurologic side effects such as seizures in the anesthetized rats ( $\mathrm{Gu}$ et al., 2007). However, despite the potential toxicological concern, there is a lack of their pharmacokinetic data about nontoxic doses as well as therapeutic doses, making it difficult to know whether their neurologic toxicity may have any effects on the therapeutic effects. In the present study, compound $2 \mathrm{e}$ raised no serious safety concerns with no abnormal behavior in rats at repeated high dosage (50 mg/kg per day). More importantly, our pharmacokinetic data revealed that the enhanced IMCL breakdown and improved glucose homeostasis by compound 2e treatment were observed at much lower plasma concentrations than those of nontoxic doses. These results confirm the antidiabetic effects of compound 2e without toxicological concerns and encourage further toxicological studies to fully characterize safety profiles of compound $2 \mathrm{e}$.

In the long-term efficacy studies, compound 2e treatment improved insulin-stimulated glucose disposal but did not significantly affect plasma insulin levels in db/db mice, indicating that the improvement of whole-body insulin resistance plays an important role in the glucose-lowering effects of compound 2e. Although the detailed mechanism underlying antidiabetic effects of compound $2 \mathrm{e}$ has not been identified, the acute and robust IMCL reductions by compound $2 \mathrm{e}$ treatment are likely to primarily contribute to the enhancement of insulin sensitivity. Recently, among IMCL species, long-chain acyl-CoA, ceramide, and diacylglycerol have been reported to directly impair insulin action and be especially important for the development of type 2 diabetes (Yu et al., 2002; Adams et al., 2004; Stratford et al., 2004; Szendroedi et al., 2014). Genetic deletion of ACC2 has been shown to reduce long-chain acyl-CoA and diacylglycerol levels and enhance insulin signaling in skeletal muscle (Choi et al., 2007). Thus, further investigations of compound $2 \mathrm{e}-$-induced changes in IMCL composition may provide mechanistic explanations for the therapeutic effects of ACC2 inhibition. Additionally, because ACC2 can play key roles in regulating hepatic and adipose tissue metabolism (Abu-Elheiga et al., 2003, 2012; Oh et al., 2005), future studies focusing on these tissues are warranted to expand understanding of the overall benefit of pharmacological ACC2 inhibition.

In the present study, we observed that chronic treatment of compound 2e resulted in greater body weight than that of vehicle treatment in $\mathrm{db} / \mathrm{db}$ mice, inconsistent with previous reports of high-fat diet studies with ACC2 knockout mice (Choi et al., 2007; Takagi et al., 2018). Several works have 
shown that body weight gain of $\mathrm{db} / \mathrm{db}$ mice disappears along with the progression of diabetic phenotype, and antidiabetic treatments contribute to their continuous body weight gain (Gibbs et al., 1995; Arakawa et al., 2001). Thus, the greater body weight, which was observed only in the later period of the experiment, may be accounted for by the amelioration in hyperglycemia and insulin sensitivity by compound $2 \mathrm{e}$ treatment.

In summary, we demonstrated that compound $2 \mathrm{e}$, a recently discovered ACC2 inhibitor, improved insulin resistance and hyperglycemia in $\mathrm{db} / \mathrm{db}$ mice. Importantly, these beneficial effects of compound 2e were linked with activation of on-target metabolic pathways and were not accompanied with ACC2independent actions that were observed in previously reported ACC2 inhibitors. Our findings provide strong evidence that pharmacological inhibition of ACC2 is a promising approach for treating type 2 diabetes.

\section{Acknowledgments}

The authors thank Kazuyoshi Tomita for conducting the mouse pharmacological studies, Kumi Hashimoto for measuring the acylcarnitine levels, Yuto Kashiwagi for measuring the IMCL and EMCL levels, and Shionogi Techno Advance Research Co., Ltd. for the skillful technical assistance with the animal experiments. The authors also thank Yuji Nishiura and Naotake Kobayashi for the compound synthesis.

\section{Authorship Contributions}

Participated in research design: Takagi, Tanimoto, Shimazaki.

Conducted experiments: Takagi, Tanimoto, Shimazaki, Tonomura, Momosaki.

Performed data analysis: Takagi, Tanimoto, Tonomura, Momosaki, Sakamoto, Abe.

Wrote or contributed to the writing of the manuscript: Takagi, Notoya, Yukioka.

\section{References}

Abu-Elheiga L, Brinkley WR, Zhong L, Chirala SS, Woldegiorgis G, and Wakil SJ (2000) The subcellular localization of acetyl-CoA carboxylase 2. Proc Natl Acad Sci USA 97:1444-1449.

Abu-Elheiga L, Oh W, Kordari P, and Wakil SJ (2003) Acetyl-CoA carboxylase 2 mutant mice are protected against obesity and diabetes induced by high-fat/highcarbohydrate diets. Proc Natl Acad Sci USA 100:10207-10212.

Abu-Elheiga L, Matzuk MM, Kordari P, Oh W, Shaikenov T, Gu Z, and Wakil SJ (2005) Mutant mice lacking acetyl-CoA carboxylase 1 are embryonically lethal. Proc Natl Acad Sci USA 102:12011-12016.

Abu-Elheiga L, Wu H, Gu Z, Bressler R, and Wakil SJ (2012) Acetyl-CoA carboxylase $2^{-/-}$mutant mice are protected against fatty liver under high-fat, high-carbohydrate dietary and de novo lipogenic conditions. J Biol Chem 287:12578-12588.

Adams JM II, Pratipanawatr T, Berria R, Wang E, DeFronzo RA, Sullards MC, and Mandarino LJ (2004) Ceramide content is increased in skeletal muscle from obese insulin-resistant humans. Diabetes 53:25-31.

Arakawa K, Ishihara T, Oku A, Nawano M, Ueta K, Kitamura K, Matsumoto M, and Saito A (2001) Improved diabetic syndrome in C57BL/KsJ-db/db mice by oral administration of the $\mathrm{Na}(+)$-glucose cotransporter inhibitor T-1095. $\mathrm{Br}$ $J$ Pharmacol 132:578-586.

Brownsey RW, Boone AN, Elliott JE, Kulpa JE, and Lee WM (2006) Regulation of acetyl-CoA carboxylase. Biochem Soc Trans 34:223-227.

Choi CS, Savage DB, Abu-Elheiga L, Liu ZX, Kim S, Kulkarni A, Distefano A, Hwang YJ, Reznick RM, Codella R, et al. (2007) Continuous fat oxidation in acetyl-CoA carboxylase 2 knockout mice increases total energy expenditure, reduces fat mass, and improves insulin sensitivity. Proc Natl Acad Sci USA 104:16480-16485.

Gibbs EM, Stock JL, McCoid SC, Stukenbrok HA, Pessin JE, Stevenson RW, Milici AJ, and McNeish JD (1995) Glycemic improvement in diabetic db/db mice by overexpression of the human insulin-regulatable glucose transporter (GLUT4). $J$ Clin Invest 95:1512-1518.

Glund S, Schoelch C, Thomas L, Niessen HG, Stiller D, Roth GJ, and Neubauer H (2012) Inhibition of acetyl-CoA carboxylase 2 enhances skeletal muscle fatty acid oxidation and improves whole-body glucose homeostasis in $\mathrm{db} / \mathrm{db}$ mice. Diabetologia 55:2044-2053.

Goodpaster BH, He J, Watkins S, and Kelley DE (2001) Skeletal muscle lipid content and insulin resistance: evidence for a paradox in endurance-trained athletes. $J$ Clin Endocrinol Metab 86:5755-5761.
Gu YG, Weitzberg M, Clark RF, Xu X, Li Q, Lubbers NL, Yang Y, Beno DW, Widomski DL, Zhang T, et al. (2007) N-\{3-[2-(4-alkoxyphenoxy)thiazol-5-yl]-1methylprop-2-ynyl)carboxy derivatives as acetyl-coA carboxylase inhibitorsimprovement of cardiovascular and neurological liabilities via structural modifications. J Med Chem 50:1078-1082.

Gu YG, Weitzberg M, Clark RF, Xu X, Li Q, Zhang T, Hansen TM, Liu G, Xin Z, Wang $\mathrm{X}$, et al. (2006) Synthesis and structure-activity relationships of N-\{3-[2-(4-alkoxyphenoxy)thiazol-5-yl]-1- methylprop-2-ynyl]carboxy derivatives as selective acetyl-CoA carboxylase 2 inhibitors [published correction appears in J Med Chem (2006) 49:5028]. J Med Chem 49:3770-3773.

Hoehn KL, Turner N, Cooney GJ, and James DE (2012) Phenotypic discrepancies in acetyl-CoA carboxylase 2-deficient mice. J Biol Chem 287:15801, author reply 15802

Hoehn KL, Turner N, Swarbrick MM, Wilks D, Preston E, Phua Y, Joshi H, Furler SM, Larance M, Hegarty BD, et al. (2010) Acute or chronic upregulation of mitochondrial fatty acid oxidation has no net effect on whole-body energy expenditure or adiposity. Cell Metab 11:70-76.

Imai S, Naito S, Takahashi T, Yamauchi A, Nakamura E, Sato M, Mitsuda Y, Takagi H, Numata Y, Fujii I, et al. (2015) Development of an ultrasensitive immunoassay using affinity maturated antibodies for the measurement of rodent insulin. Anal Biochem 473:72-79.

Kelley DE, Goodpaster B, Wing RR, and Simoneau JA (1999) Skeletal muscle fatty acid metabolism in association with insulin resistance, obesity, and weight loss. Am J Physiol 277:E1130-E1141.

Kim H, Haluzik M, Asghar Z, Yau D, Joseph JW, Fernandez AM, Reitman ML, Yakar S, Stannard B, Heron-Milhavet L, et al. (2003) Peroxisome proliferator-activated receptor-alpha agonist treatment in a transgenic model of type 2 diabetes reverses the lipotoxic state and improves glucose homeostasis. Diabetes 52:1770-1778.

Kim JY, Hickner RC, Cortright RL, Dohm GL, and Houmard JA (2000) Lipid oxidation is reduced in obese human skeletal muscle. Am J Physiol Endocrinol Metab 279:E1039-E1044

Krssak M, Falk Petersen K, Dresner A, DiPietro L, Vogel SM, Rothman DL, Roden M, and Shulman GI (1999) Intramyocellular lipid concentrations are correlated with insulin sensitivity in humans: a ${ }^{1} \mathrm{H}$ NMR spectroscopy study. Diabetologia 42: 113-116.

McGarry JD and Brown NF (1997) The mitochondrial carnitine palmitoyltransferase system. From concept to molecular analysis. Eur J Biochem 244:1-14.

Morino K, Petersen KF, and Shulman GI (2006) Molecular mechanisms of insulin resistance in humans and their potential links with mitochondrial dysfunction. Diabetes 55 (Suppl 2):S9-S15.

Nishiura Y, Matsumura A, Kobayashi N, Shimazaki A, Sakamoto S, Kitade N, Tonomura Y, Ino A, and Okuno T (2018) Discovery of a novel olefin derivative as a highly potent and selective acetyl-CoA carboxylase 2 inhibitor with in vivo efficacy. Bioorg Med Chem Lett 28:2498-2503.

Oh W, Abu-Elheiga L, Kordari P, Gu Z, Shaikenov T, Chirala SS, and Wakil SJ (2005) Glucose and fat metabolism in adipose tissue of acetyl-CoA carboxylase 2 knockout mice. Proc Natl Acad Sci USA 102:1384-1389.

Olson DP, Pulinilkunnil T, Cline GW, Shulman GI, and Lowell BB (2010) Gene knockout of Acc2 has little effect on body weight, fat mass, or food intake. Proc Natl Acad Sci USA 107:7598-7603.

Stratford S, Hoehn KL, Liu F, and Summers SA (2004) Regulation of insulin action by ceramide: dual mechanisms linking ceramide accumulation to the inhibition of Akt/protein kinase B. J Biol Chem 279:36608-36615.

Szendroedi J, Yoshimura T, Phielix E, Koliaki C, Marcucci M, Zhang D, Jelenik T, Müller J, Herder C, Nowotny P, et al. (2014) Role of diacylglycerol activation of $\mathrm{PKC} \theta$ in lipid-induced muscle insulin resistance in humans. Proc Natl Acad Sci USA 111:9597-9602.

Takagi H, Ikehara T, Kashiwagi Y, Hashimoto K, Nanchi I, Shimazaki A, Nambu H, and Yukioka H (2018) ACC2 deletion enhances IMCL reduction along with acetyl$\mathrm{CoA}$ metabolism and improves insulin sensitivity in male mice. Endocrinology 159: 3007-3019.

Virkamäki A, Korsheninnikova E, Seppälä-Lindroos A, Vehkavaara S, Goto T, Halavaara J, Häkkinen AM, and Yki-Järvinen H (2001) Intramyocellular lipid is associated with resistance to in vivo insulin actions on glucose uptake, antilipolysis, and early insulin signaling pathways in human skeletal muscle. Diabetes 50:2337-2343.

Wakil SJ and Abu-Elheiga LA (2009) Fatty acid metabolism: target for metabolic syndrome. J Lipid Res 50 (Suppl):S138-S143.

Waring JF, Yang Y, Healan-Greenberg CH, Adler AL, Dickinson R, McNally T, Wang X, Weitzberg M, Xu X, Lisowski A, et al. (2008) Gene expression analysis in rats treated with experimental acetyl-coenzyme A carboxylase inhibitors suggests interactions with the peroxisome proliferator-activated receptor alpha pathway. J Pharmacol Exp Ther 324:507-516.

Ye JM, Doyle PJ, Iglesias MA, Watson DG, Cooney GJ, and Kraegen EW (2001) Peroxisome proliferator-activated receptor (PPAR)-alpha activation lowers muscle lipids and improves insulin sensitivity in high fat-fed rats: comparison with PPARgamma activation. Diabetes 50:411-417.

Yu C, Chen Y, Cline GW, Zhang D, Zong H, Wang Y, Bergeron R, Kim JK, Cushman SW, Cooney GJ, et al. (2002) Mechanism by which fatty acids inhibit insulin activation of insulin receptor substrate-1 (IRS-1)-associated phosphatidylinositol 3kinase activity in muscle. J Biol Chem 277:50230-50236.

Address correspondence to: Hiroyuki Takagi, Drug Discovery \& Disease Research Laboratory, Shionogi \& Co., Ltd., 3-1-1, Futaba-cho, Toyonaka, Osaka 561-0825, Japan. E-mail: hiroyuki.takagi@shionogi.co.jp 